\title{
Clinical, laboratory and molecular signs of immunodeficiency in patients with partial oculo-cutaneous albinism
}

\author{
Laura Dotta', Silvia Parolini ${ }^{2}$, Alberto Prandini ${ }^{1}$, Giovanna Tabellini ${ }^{2}$, Maddalena Antolini ${ }^{1}$, \\ Stephen F Kingsmore ${ }^{3}$ and Raffaele Badolato ${ }^{1,4^{*}}$
}

\begin{abstract}
Hypopigmentation disorders that are associated with immunodeficiency feature both partial albinism of hair, skin and eyes together with leukocyte defects. These disorders include Chediak Higashi (CHS), Griscelli (GS), Hermansky-Pudlak (HPS) and MAPBP-interacting protein deficiency syndromes. These are heterogeneous autosomal recessive conditions in which the causal genes encode proteins with specific roles in the biogenesis, function and trafficking of secretory lysosomes. In certain specialized cells, these organelles serve as a storage compartment. Impaired secretion of specific effector proteins from that intracellular compartment affects biological activities. In particular, these intracellular granules are essential constituents of melanocytes, platelets, granulocytes, cytotoxic T lymphocytes (CTLs) and natural killer (NK) cells. Thus, abnormalities affect pigmentation, primary hemostasis, blood cell counts and lymphocyte cytotoxic activity against microbial pathogens. Among eight genetically distinct types of HPS, only type 2 is characterized by immunodeficiency. Recently, a new subtype, HPS9, was defined in patients presenting with immunodeficiency and oculocutaneous albinism, associated with mutations in the pallidin-encoding gene, PLDN. Hypopigmentation together with recurrent childhood bacterial or viral infections suggests syndromic albinism. T and NK cell cytotoxicity are generally impaired in patients with these disorders. Specific clinical and biochemical phenotypes can allow differential diagnoses among these disorders before molecular testing. Ocular symptoms, including nystagmus, that are usually evident at birth, are common in patients with HPS2 or CHS. Albinism with short stature is unique to MAPBP-interacting protein (MAPBPIP) deficiency, while hemophagocytic lymphohistiocytosis (HLH) mainly suggests a diagnosis of CHS or GS type 2 (GS2). Neurological disease is a long-term complication of CHS, but is uncommon in other syndromic albinism. Chronic neutropenia is a feature of HPS2 and MAPBPIP-deficiency syndrome, whereas it is usually transient in CHS and GS2. In every patient, an accurate diagnosis is required for prompt and appropriate treatment, particularly in patients who develop HLH or in whom bone marrow transplant is required. This review describes the molecular and pathogenetic mechanisms of these diseases, focusing on clinical and biochemical aspects that allow early differential diagnosis.
\end{abstract}

Keywords: Primary immunodeficiency, Natural killer cells, Hemophagocytosis, Partial albinism

\footnotetext{
* Correspondence: badolato@med.unibs.it

${ }^{1}$ Department of Experimental and Clinical Sciences, Institute of Molecular

Medicine "Angelo Nocivelli", University of Brescia, Brescia, Italy

${ }^{4}$ Istituto di Medicina Molecolare "Angelo Nocivelli", Universita' di Brescia,

c/o Spedali Civili, Brescia 25123, Italy

Full list of author information is available at the end of the article
} 


\section{Introduction}

Hypopigmentation syndromes represent a readily distinguished group of diseases. Pigment dilution may involve skin, hair and iris, and generally is manifest at birth. Genetic defects of melanin biosynthesis are inherited as autosomal recessive Oculocutaneous Albinism (OCA) or X-linked Ocular Albinism (OA), in which abnormal pigmentation is an isolated manifestation [1]. However, hypopigmentation may also represent a feature of genetic disorders characterized by immunodeficiency, including Chediak Higashi Syndrome (CHS), Griscelli Syndrome (GS), Hermansky-Pudlak type 2 Syndrome (HPS2) and MAPBPIP-deficiency Syndrome. Recently a new form of HPS-like syndrome, known as HSP-9, has been added to the causes of immunodeficiency-associated albinism.

All causal genes that have been linked to albinism appear to play a role in the biogenesis, function or trafficking of intracellular organelles, particularly of secretory lysosomes [2]. Cell types containing secretory lysosomes include melanocytes, hematopoietic cells and renal tubular cells. In melanocytes, secretory lysosomes are known as melanosomes, and are involved in melanin pigment secretion. Among cells of hematopoietic lineage, the cytotoxicity of $\mathrm{T}$ and Natural Killer (NK) cells requires tightly regulated secretion of cytolytic enzymes stored in secretory lysosomes. In addition, antigen presentation to $\mathrm{T}$ cells by macrophages, dendritic cells and $\mathrm{B}$ cells involves MHC-class-II positive secretory lysosomes for proper transport and processing of endocytic antigens [2]. Finally, primary hemostasis is mediated by platelet clotting agents, stored in secretory lysosomes, while, neutrophil antimicrobial activity depends upon regulated release of cytosolic granules.

Defects in proteins involved in the function of secretory lysosomes affect biological activity of these cells leading to hypopigmentation and various degrees of immunodeficiency $[3,4]$. A thorough evaluation of a patient presenting with partial albinism and immunodeficiency will feature clinical, laboratory and molecular aspects aiming to a prompt diagnosis and effective treatment.

\section{Disease name}

Partial Oculocutaneous Albinism and Immunodeficiency (OCA-ID).

\section{Definition}

Partial Oculocutaneous Albinism and Immunodeficiency (OCA-ID) is a group of five autosomal recessive syndromes clinically characterized by hypopigmentation of skin, hair and eyes, associated with recurrent infections. While these diseases have similar cutaneous and ocular manifestations, including partial albinism, nystagmus and strabismus, the hematologic symptoms can be extremely heterogeneous and vary from mild bleeding, as seen in
HPS2 patients, to hemophagocytic syndrome, as observed in CHS and GS2 patients. All patients with OCA-ID display a moderate to high susceptibility to both viral and bacterial infections that can manifest variously as delayed clearance of herpes viruses, and often by respiratory and cutaneous bacterial infections. Defective cytotoxicity of both NK and cytotoxic T cells (CTL) is observed in all patients with OCA-ID, but to a variable extent, being more severe in patients with CHS and GS2. Neutropenia is a chronic feature in HPS2 and in MAPBPIPdeficiency, but can be transiently observed in the other conditions [Table 1].

\section{Epidemiology}

Partial Albinism and Immunodeficiency disorders are extremely rare. Each of them has a prevalence of $<1 / 1,000,000$ without crossover-enrichment in selected populations.

Patients presenting with oculo cutaneous albinism and hemophagocytic lymphohistiocytosis Hemophagocytic lymphohistiocytosis (HLH)

HLH represents a life-threatening condition commonly affecting about $50-85 \%$ of $\mathrm{CHS}$ patients within the first decade and, in the case of the majority of GS2 patients, frequently in the first year of life [5,6]. A single case of HLH has been reported in one patient with HPS2.

HLH is a severe hyperinflammatory disease caused by uncontrolled but ineffective immune response. It is also known as "accelerated phase": it manifests as prolonged fever, lymphadenopathy, hepatosplenomegaly, signs of liver dysfunction (including jaundice, elevated transaminases, hypofibrinogenemia and/or hypertriglyceridemia, high level of ferritin and lactate dehydrogenase), cytopenia of at least two hematopoietic cell lineages (commonly neutropenia, anemia, thrombocytopenia or pancytopenia) [7]. Neurological manifestations, ranging from cranial nerve palsy to seizures and decreased level of consciousness, may occur. Cerebrospinal fluid shows pleocytosis, increased proteins, or both [8]. Histopathology reveals lymphoproliferative infiltration of bone marrow and reticuloendothelial system. The cause is a defective cytotoxic activity leading to impaired down regulation of immune response and sustained activation and proliferation of CTL and NK cells [9]. These cells produce large amounts of cytokines (such as IFNy, TNFalpha, GM-CSF) activating macrophages and dendritic cells. The latter migrate to sites of inflammation, thus infiltrating tissues and organs and producing high levels of proinflammatory cytokines and chemokines that are responsible for the laboratory signs and symptoms of HLH. Therefore, diagnosis is based on clinical and laboratory criteria, according to the guidelines of the Hystiocyte Society lastly revised in 2007. For the diagnosis of HLH, five out of eight criteria are required; they are: prolonged fever, enlarged spleen, 
Table 1 Primary Immunodeficiencies that associated with oculocutaneous albinism

\begin{tabular}{|c|c|c|c|c|c|c|c|c|c|c|}
\hline & Locus & $\begin{array}{c}\text { Oculocutaneous } \\
\text { albinism }\end{array}$ & $\begin{array}{l}\text { Bleeding } \\
\text { disorders }\end{array}$ & $\begin{array}{l}\text { Short } \\
\text { stature }\end{array}$ & $\begin{array}{l}\text { Neurological } \\
\text { symptoms }\end{array}$ & HLH & Neutropenia & $\begin{array}{c}\text { NKs } \\
\text { defects }\end{array}$ & $\begin{array}{c}\text { CTLs } \\
\text { defects }\end{array}$ & $\begin{array}{c}\text { Giant } \\
\text { granules }\end{array}$ \\
\hline $\mathrm{CHS}$ & $\mathrm{CHS1}$ & + & + & - & + & + & $+/-^{*}$ & + & + & + \\
\hline GS2 & RAB27A & + & - & - & - & + & $+/-^{*}$ & + & + & - \\
\hline HPS2 & ADTB3A & + & + & - & - & + & + & + & + & - \\
\hline HPS9 & PLDN & + & - & - & - & - & - & + & $\mathrm{N} / \mathrm{A}$ & - \\
\hline MAPBPIP deficiency & LAMTOR2 & + & - & + & - & - & + & + & + & - \\
\hline
\end{tabular}

*Transient neutropenia can be observed.

CHS Chediak-Higashi syndrome; GS2 Griscelli syndrome type 2; HPS-2 Hermanski-Pudlak syndrome-type 2; HLH hemophagocytic lymphohistiocytosis.

low or absent NK cell function, abnormalities in two or more blood cell lineages, increased triglycerides or reduced fibrinogen, increased serum ferritin, evidence of hemophagocytosis in bone marrow but not malignancy, abnormally high soluble CD25 in blood as sign of T-cell activation.

Moreover, HLH may occur during the course of Epstein-Barr virus infections, when it may resemble lymphoma [10]. In patients who present with HLH as the first manifestation of disease and with mild or absent symptoms of OCA-ID, other inherited forms of HLH may be considered. Familial hemophagocytic lymphohistiocytosis is also genetically heterogeneous. There are five genetically distinct types which share an autosomal recessive pattern of inheritance. The causal genes are known for four types, and belong to the cytolytic granule-dependent exocytosis pathway. They are perforin (FHL2), UNC13D (FHL3), syntaxin-11 (FHL4), syntaxin-binding protein-2 (FHL5). In these cases, HLH represents the primary and only manifestation of immunodeficiency [11]. If untreated, HLH may be fatal within a few weeks. HSCT is strongly indicated as the only curative treatment.

\section{Chediak-higashi syndrome}

$\mathrm{CHS}$ is an autosomal recessive disorder characterized by partial albinism associated with immune dysfunction, bleeding diathesis and progressive neurologic deterioration. The risk of hemophagocytic lymphohistiocytosis is estimated at $85 \%[5,12-14]$.

\section{Clinical phenotype}

Partial Albinism. Patients present a variable degree of hypopigmentation affecting skin, hair and eyes [5,14]. Skin color can vary from milky-white to slate gray, and hypopigmentation is often appreciated only by comparison with other family members. Skin hypopigmentation is associated with increased risk of sun damage and skin cancer; uncommonly, CHS may present with hyperpigmentation, leading to suspicion of other photosensitivity diseases characterized by hyperpigmentation with consequent delay in diagnosis [15]. Hair color may appear blonde to light brown, often with a distinguished silvery or metallic sheen. Iris hypopigmentation may be associated with decreased retinal pigmentation, nystagmus and impaired visual acuity.

Infections. The clinical history in CHS is typically remarkable for recurrent and severe bacterial infections since childhood [14]. Skin and respiratory tract are mainly involved; Staphylococcus and Streptococcus are the species most frequently isolated. Viral and fungal infections, however, have also been described. According to recent reports, severe periodontitis may also be an indication to raise suspicion of CHS [16].

Bleeding diathesis. Patients present a prolonged bleeding time and may manifest mildly disordered platelet aggregation, including epistaxis, gum/mucosal bleeding, petechiae, and easy bruising, that do not usually require any treatment $[5,14]$.

Neurological manifestations. Patients who survive into early adulthood may develop motor and sensory neuropathies, balance abnormalities, ataxia, tremor, absent deeptendon reflexes, and low cognitive abilities. In addition, neurologic symptoms can also be observed in older patients presenting with an atypical, milder form of $\mathrm{CHS}$, manifesting with dementia, parkinsonism, peripheral neuropathy $[5,14]$.

\section{Molecular genetics and mechanisms}

The human gene identified as causal for CHS, LYST/ CHS1, is located at chromosome 1q42.1-q42.2 [17-19]. LYST (lysosomal trafficking regulator) is a cytosolic protein of approximately $430 \mathrm{kDa}$ which is highly conserved through evolution and is expressed at low levels in all cell types [20]. Its precise function remains unknown but it is hypothesized its role in regulating lysosome size and trafficking, particularly by regulating membrane fission/fusion events $[21,22]$. The pathognomonic feature of CHS is the presence of giant lysosomes and lysosomerelated organelles in all cell types [23,24]. While the degradative function of lysosomes might be conserved, the exocytic pathway of secretory lysosomes is impaired in leukocytes of $\mathrm{CHS}$ patients. All mutations identified to date are missense or nonsense substitutions, small coding deletions or insertions that often result in protein truncation or nonsense mediated decay. A correlation between 
specific genotypes and clinical phenotypes has been hypothesized: loss-of-function mutations are associated with severe, childhood-onset forms, while missense mutations occur in milder adolescent- or adult-onset forms of the disease $[25,26]$. In addition, other studies suggest a relation between the extent of the cellular defect and the clinical phenotype [27]. Recently two novel heterogeneous mutations have been discovered, but their relationship with the clinical phenotype remains unclear [28]. Each clinical manifestation of CHS is associated with a defect of a specific cell type and to the formation of secretory enlarged lysosomes in these cells [29-34]. Bleeding diathesis is related to the decreased pool of platelet dense granules that is needed for a normal aggregation response, while antimicrobial activity defect is due to the reduced amount of neutrophil enzymes, as well as the impaired exocytosis of lytic proteins is responsible for the impairment of NK and CTL cell cytotoxicity. Pigment dilution is related to the defective migration of giant melanosomes from the melanocyte dendrites to surrounding keratinocytes. Therefore, the presence of giant organelles may affect neutrophil chemotaxis and degranulation as well as giant inclusions. In neuronal cells, formation of giant granules might have a role in the pathogenesis of the neurological manifestations of CHS patients.

\section{Management}

Episodes of infection, clinical and ophthalmological findings may suggest the diagnosis of CHS. Clinical diagnosis is firstly supported by the presence of peroxidase-positive giant inclusions in white blood cells, by detection of pigment clumping in the light microscopy analysis of hair and eventually by studies revealing abnormal platelet aggregation [14]. Electron microscopy can demonstrate reduced number and irregular morphology of platelet dense-bodies [29,30]. Of note, giant granules resembling those seen in CHS may be revealed in acute and chronic myeloid leukemia. NK cell counts are generally normal but cytotoxic activity is impaired [33]. Neutropenia may coexist with abnormal functioning (typically chemotaxis and intracellular bactericidal activity) [32]. Immunoglobulin levels, complement are generally normal while delayed hypersensitivity may be impaired. Definitive diagnosis is based on molecular genetic testing of LYST. Of note, cases of neurological involvement, subtle albinism, bleeding manifestations, even without history for recurrent infections, may be considered for atypical and mild phenotypes of CHS [5]. Prognosis is poor because death frequently occurs in the first decade of life due to infections or development of HLH. Treatment of infections requires prompt and aggressive antimicrobial therapies; while prophylaxis should be considered according to the frequency of infectious episodes. A prompt diagnosis of $\mathrm{CHS}$ can prevent the development of HLH by initiating appropriate treatments. The most effective treatment for the hematological and immune defects of CHS is HSCT, albeit there is no evidence of efficacy in delaying or preventing progressive neurological dysfunction $[35,36]$.

\section{Griscelli syndrome type 2}

Griscelli syndrome is a rare autosomal recessive disorder first described in 1978 as partial albinism associated with immunodeficiency [37]. Type 2 Griscelli syndrome can be distinguished from the other two forms of this disorder on the basis of distinctive clinical and molecular features. Griscelli syndrome type 1 (GS1) features primary neurological disease and pigment anomalies and it is caused by mutations in the MYO5A gene encoding the motor protein myosin-Va [38]. The clinical features of type 3 (GS3) are restricted to hypopigmentation of skin, and hair. GS3 is caused by mutations in the melanophilin gene $M L P H$ [39]. Among GS subtypes, only patients with type 2 commonly may develop HLH.

\section{Clinical phenotype}

Children with GS2 frequently present with silver-gray hair and relatively light skin color. Usually they have an increased susceptibility to recurrent pyogenic infections and may present with recurrent episodes of fever, hepatosplenomegaly and lymphadenopathy [40]. In the majority of GS2 patients, the development of HLH, known also as the "accelerated phase", occurs from 6 to 12 months of age [6]. While neurological symptoms can be observed in GS2 patients, they are related to the development of HLH in these subjects, as the gene $R A B 27 A$ associated with GS2 is not expressed in neuronal cells.

\section{Molecular genetics and mechanisms}

GS2 is caused by mutations in the RAB27A gene, which maps to chromosome 15q21 and encodes a small GTPase that regulates vesicular fusion and trafficking. In particular Rab27a is required for peripheral anchorage of melanosomes in melanocytes, as well as exocytosis of cytolytic granules in CTL and NK cells. In addition, Rab27a is crucial for docking of cytolytic granules to the plasma membrane secondary to target-cell recognition and TCR signal activation $[6,41,42]$.

\section{Management}

Most commonly the diagnosis of GS2 occurs between 4 months and 7 years [40]. Parental consanguinity and a history of familial deaths may be suggestive. Clinical suspicion of GS2 can be supported by light microscopic examination of hair shafts, typically showing irregular large clumps of melanin pigment. Electron microscopic evaluation of skin reveals numerous mature melanosomes in melanocytes with few melanosomes in adjacent 
keratinocytes $[37,40]$. Giant granules are absent in peripheral leukocytes. Defects of adaptive immunity are variable: laboratory tests may reveal defective NK cytoxicity together with an impaired delayed-type hypersensitivity response [41]. Commonly, however, granulocyte and lymphocyte count and functions are normal, while immunoglobulin levels may be normal, decreased or increased. As discussed below, since HLH typically develops in GS2, the disease is fatal without HSCT $[43,44]$. Immunosuppressive therapy is reported to improve patient symptoms as a palliative treatment or to induce remission until HSCT can be performed [45]. There is evidence of rescue of CTL activity using a retroviral vector to mediate the transfer of RAB27A gene, opening an alternative possibility for GS2 treatment [46]. A prompt initiation of an appropriate treatment can prevent complications, including the neurological sequelae of the disease.

\section{Patients presenting with oculocutaneous albinism and neutropenia}

Hermansky pudlak syndrome type 2 (HPS2)

HPS2 belongs to a genetically heterogenous group of autosomal recessive disorders that share oculocutaneous albinism and platelet storage disease. In humans, nine causative genes have been cloned and sequenced: each defective gene is involved in formation, transport or fusion of intracellular vesicles of lysosomal lineage [47]. Type 2 represents the HPS type that was first associated to immunodeficiency, specifically neutropenia.

\section{Clinical phenotype}

Clinical signs suggestive for HPS2 may be detectable at birth [48]: they include horizontal nystagmus, ocular hypopigmentation, including iris trans-illumination and hypopigmentated areas of fundus oculi. As a consequence, decreased visual acuity is frequent. Hair color ranges from white to dark brown. Hair may be sparse and white and may darken over time. In the same way, skin varies from white to brown and often must be compared to the skin tone of other family members to be distinguished. As with other types of albinism, patients are susceptible to sun damage and there is a higher risk for skin malignancies. In childhood, distinctive facial features may become evident, in particular, epicanthal folds, posteriorly rotated ears, broad nasal root and retrognathia. HPS2 patients may have a prolonged bleeding time (up to $>15$ minutes) and manifest spontaneous soft tissue bruising and mucosal bleeding, while major hemorrhages into joints, brain or other organs are rare. Typically the first sign of a bleeding diathesis in HPS patients consists of excess bruising beginning at the time of first ambulation. Otherwise, episodes of epistaxis are frequent but often remit during adolescence. Other events that may result in excessive bleeding include dental extractions, surgeries, acute colitis, menstrual periods, and childbirth. Recurrent infections are a prominent feature of HPS2 [49]. Bacterial infections mainly include upper respiratory infections, otitis media and pneumonias. Moreover, HPS2 patients display higher susceptibility to viral infections and certain malignancies, such as Hodgkin's lymphoma [50]. The defects of cytotoxic activity that have been reported in HPS2 patients might suggest an increased risk of HLH. However, only one case of HLH in HPS2 has been described in literature. That patient was also heterozygous for a RAB27a mutation [51], suggesting that other genetic or environmental factors probably contributed to HLH development in this patient.

\section{Molecular genetics and mechanisms}

HPS2 is caused by mutations in AP3B1 gene, on chromosome $5 \mathrm{q} 14.1$, encoding the $\beta 3 \mathrm{~A}$ subunit of the heterotetrameric adapter protein (AP-) 3 complex $[49,52]$. Defects in $\beta 3 \mathrm{~A}$ subunit prevent the formation of the entire AP-3 complex. In mammalian cells there are 4 types of adaptor protein complexes that are involved in cellular protein trafficking. In particular, AP-3 directs post-translational trafficking of intraluminal cargo proteins from the transGolgi network to lysosomes [53-55]. The absence of the AP-3 complex impairs trafficking of lysosome-targeted proteins to and from lysosomes so that proteins trafficking to lysosomes will accumulate at the plasma membrane. Consequently, regulation and functioning of specific cells related to secretory lysosomes are defective $[56,57]$.

In melanosomes, there is evidence that AP- 3 regulates tyrosinase trafficking, which is essential for the synthesis of melanin. In platelets, the absence of dense granules, that contain ADP, ATP, serotonin, calcium and polyphosphates, which are required for platelet aggregation, is a typical feature of the disease.

In neutrophils, AP-3 mediates trafficking of neutrophil elastase to lysosome-like granules, known as azurophilic granules. Neutrophil elastase is required for normal differentiation of myeloid progenitor cells to mature neutrophils. Abnormal trafficking of neutrophil elastase is associated with neutropenia, although the precise mechanism remains to be defined [58]. Thus, HPS2 patients exhibit arrested maturation of neutrophil precursors at the stage of pro-myelocytes. The neutrophil count in HPS2 patients usually increases in response to infection or to Granulocyte-Colony Stimulating Factor (G-CSF) therapy $[57,58]$.

In CTLs in HPS2, defects in lytic granule trafficking and functioning are associated with impaired cytotoxicity, particularly due to failure to secrete lysosomal lytic enzymes, such as perforin and granzymes, in response to receptor signaling [56,57]. Moreover, NK cells have reduced lysosomal pools of perforin, while granzyme levels 
are normal, suggesting possible defects of NK cell differentiation.

In addition, there is evidence for a role of the AP-3 complex in antigen presentation; notably AP-3 deficiency results in impaired antigen presentation by $\mathrm{CD} 1 \mathrm{~b}$ and impaired microbial lipid antigen presentation to T-cells $[59,60]$. CD1b binding to AP-3 is required for proper localization in the MHC class II compartment, for appropriate sorting from the lysosome to the plasma membrane and for antigen presentation. In particular, there is a subset of $\mathrm{T}$ cells, known as invariant NK T-cells (iNKT) expressing a semi-invariant TCR, which confers the capacity to recognize a limited number of glycosphingolipids presented by APCs in the context of CD1b or of the murine ortholog CD1d [61,62]. As consequence, these cells can play a stimulatory role toward other immune cells or can exert immune regulatory function. Lack of AP-3 might deregulate this signaling and activation pathway contributing to NK-T cell deficiency and to susceptibility to bacterial and viral infections $[60,62]$.

\section{Diagnosis and management}

Laboratory tests reveal neutropenia in HPS2 patients. Platelet count is normal or increased but platelet aggregation response is altered, generally with an abnormal response to collagen and adenosine diphosphate, but normal response to ristocetin. Electron microscopy of platelets reveals reduction of dense bodies. Lymphocyte subpopulations and proliferative response to mitogens are generally normal. NK cells and CTL cells are normal in number or slightly reduced with an impaired cytolytic activity.

Molecular analysis of AP3B1 allows definitive diagnosis. A careful follow up is necessary to monitor when G-CSF treatment is required.

\section{Hermansky pudlak syndrome type 9: pallidin deficiency} HPS9 is the most recently defined subtype of HermanskyPudlak syndrome. It was recently described in patients presenting with clinical manifestations suggestive of HPS, but with negative molecular tests for previously known HPS types [63]. The molecular basis of HPS9 in one of the two pedigrees described was identified by exome sequencing [64].

\section{Clinical phenotype}

The two cases reported to date in the literature shared partial albinism, nystagmus, normal neurological development and absence of platelet delta granules, but lacked the bleeding manifestations typical of HPS2 [63,64]. One case had recurrent infections, especially of the skin, and transient leukopenia [64].

\section{Molecular genetics and mechanisms}

The two patients had the same homozygous mutation, c.232C $>$ T (p.Q78X), in exon 3 of the pallidin gene ( $P L D N$, chr15:45895305C $>\mathrm{T}$ ), which led to undetectable expression of the protein product in NK cells. The full length $P L D N$ transcript, which contains exon 3 , is ubiquitously expressed in adult and fetal tissues with the exception of brain. A second PLDN transcript, that has a strong expression in the brain, arises as a result of alternative splicing and skipping of exon 3, which contains the mutation observed in the two HPS9 patients [63]. Pallidin is a subunit of the protein complex BLOC-1 (biogenesis of lysosome-related organelles complex-1). To date, mutations have been described in three human BLOC-1 genes and in five mouse BLOC-1 genes. In melanocytes, the absence of pallidin may impair the stability and functioning of other BLOC-1 proteins such as syntaxin-13, which is an endosome t-SNARE (targetSNAP -Soluble N-ethylmaleimide-sensitive factor Attachment Protein- Receptor), and may alter intracellular trafficking of TYRP1, a protein which is crucial for melanosome maturation and melanin production [63]. In NK cells, pallidin regulates the expression of lysosomal membrane proteins, particularly CD107a and CD63, akin to HPS2. It has been shown that pallidin absence results in impairment of degranulation and cytolytic activity of NK cells thus leading to immune defects [64].

\section{Management}

HPS9 may be suspected together with HPS2 in patients with albinism and recurrent infections; although the two HPS9 patients did not present bleeding manifestations, further cases are needed to more fully define the clinical phenotype. Antibiotic prophylaxis can be used in patients with recurrent infections.

\section{Deficiency of endosomal adaptor protein MAPBPIP}

A recently defined primary immunodeficiency syndrome features congenital neutropenia and B-cell and CTL deficiency together with partial albinism and short stature [65].

\section{Clinical phenotype}

The reports to date in the literature describe children with recurrent bronchopulmonary infections, mainly by Streptococcus pneumonia, with the short stature as an additional pathognomonic feature [65]. The extent of albinism is variable.

\section{Molecular genetics and mechanisms}

MAPBPIP, is encoded by the LAMTOR2 gene, is an ubiquitous endosomal protein (also known as p14). It is localized on the outer membrane of late endosome, and functions 
as a scaffold molecule involved in mitogen-activated protein kinase (MAPK) signaling [66,67]. MAPBPIP plays an essential role in many cellular functions such as subcellular compartmentalization of signals and cellular responses to cell surface receptor signaling, as evidenced by early lethality in Lamtor2 knock-out mice [65]. A homozygous point mutation in the 3'UTR of LAMTOR2 located on chromosome 1q21 causes decreased LAMTOR2 mRNA expression and consequently decreased protein levels. Aberrant lysosome function due to MAPBPIP deficiency affects neutrophils, B cells, CTLs and melanocytes. Neutrophils show an altered ultrastructure of azurophilic granules and decreased microbiocidal activity in phagosomes. In MAPBPIP-deficient cells, cytokine-receptor-mediated ERK phosphorylation is defective and a marked delocalization of late endosomes can be observed.

\section{Management}

Recurrent bacterial infections and growth delay in a patient affected by severe peripheral neutropenia may be suggestive for this new form of OCA-ID. Neutrophil maturation in bone marrow is supposed to be preserved. To date, in MAPBPIP deficiency syndrome immunological tests reveal decreased CTL cytotoxicity, and increased number of naïve $B$ cells but a reduced number of memory B cells [65]. Definitive diagnosis depends on molecular analysis demonstrating mutations in MAPBPIP gene. Treatment with G-CSF is required to reduce frequency and severity of infections.

\section{Differential diagnosis}

Hypopigmentation of skin, hair and eyes can be easily observed at birth in the majority of patients with oculocutaneous albinism, while the degree of hypopigmentation is variable, often according to parent's pigmentation. Depigmentation is commonly extensive in HPS2 and $\mathrm{CHS}$ patients and affects skin, coloring from white to gray, hair, tingling from blonde to light brown, or with a silvery or metallic sheen typical of CHS, and eyes appearing gray, blue or rarely brown $[5,48]$. In GS2, hypopigmentation affects skin and hair, which is typically silvery-gray [41], while in MAPBPIP deficiency albinism is variable and the pathognomonic sign is the short stature [65]. Ocular symptoms, particularly nystagmus, iris translucency and reduced retinal pigmentation, are similarly present in neonates, in patients with CHS or HPS2. Symptoms related to immunodeficiency usually become evident in childhood and therefore, at birth, the phenotype of OCA-ID disorders cannot be easily distinguished from other causes of albinism [1]. Similar ocular and cutaneous features can be found in patients with HermanskyPudlak syndromes (HPS1-8), but these patients may also have mild bleeding defects and, at later ages, interstitial pulmonary fibrosis. Other rare inherited disorders that should be excluded in patients with albinism are Waardenburg Syndrome type II (WS2), which is associated with sensor-neural deafness, and Griscelli syndrome type 1, which is also characterized by neurological disorders and by a unique distribution of pigment in hair. Although differential diagnosis of OCA-ID within these inherited disorders can be easy at later ages, after observation of repeated episodes of infections, the diagnosis should not be delayed if OCA-ID is suspected because invasive infections may be fatal in such patients. Moreover, neurological symptoms appear along time in CHS patients, being characterized mainly by peripheral neuropathy [14]. HLH occurs primarily in CHS and GS2 [5,6]. Only one case of HLH has been reported in HPS2 [51]. Given the limited number of cases, it is impossible to define the risk of HLH in patients with $\mathrm{p} 14$ or pallidin deficiency. HLH is a life threatening condition that may be prevented with the appropriate treatment when diagnosis is defined. Therefore, when one of these disorders is suspected, microscopic, immunological and genetic studies should be promptly performed.

In CHS, microscopic evaluation of hair shafts reveals regular small melanin aggregates, while in GS2 irregular large clumps of melanin pigment are characteristic. Moreover, microscopic evaluation of skin shows in CHS giant melanosomes both in keratinocytes and melanocytes; while in GS2, epidermal melanocytes are filled with numerous mature melanosomes and adjacent keratinocytes with only rare melanosomes. Evaluation of neutrophil organelle morphology and count is useful in CHS, HPS2 and MAPBPIP deficiency, but unrevealing in GS2. Neutropenia is chronic in HPS2 and MAPBPIP deficiency, while it can be transiently observed in CHS and GS2. Neutrophil functions, including bactericidal activity, chemotaxis and degranulation, are defective only in CHS, where microscopic examination of peripheral blood smear reveals giant inclusions that are typical of this disorder [24]. For prompt identification of OCA-ID, evaluation of NK or CTL cytotoxic activity against susceptible cells is important, because it is impaired in all these syndromes. Immunoglobulin levels are typically normal in HPS2 and CHS patients, while in GS2 immunoglobulin may be increased or reduced. In MAPBPIP deficiency, B-memory cells are reduced, with consistently decreased serum IgM levels [65]. In CHS and GS2, delayed hypersensitivity may be impaired, while no alterations are described in the other syndromes [14]. Functional platelet studies reveal defects in aggregation, while their count is normal or increased in HPS2 and CHS. Molecular genetic testing is the gold standard for definitive diagnosis. Newer approaches, such as genome, exome or gene panel sequencing, are starting to be employed for differential diagnosis of disorders such as these, where there is substantial genetic heterogeneity [68-76]. 


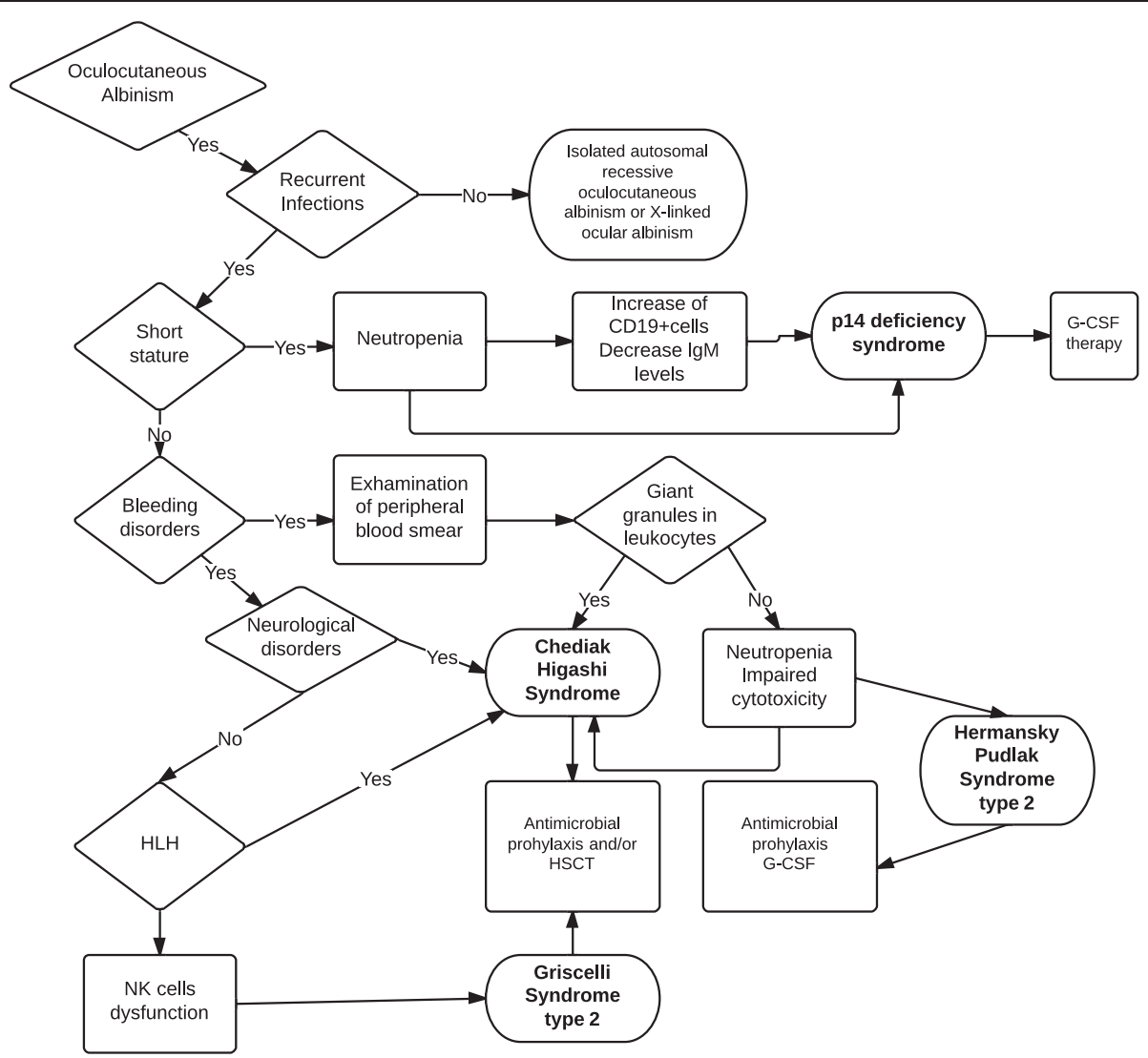

Figure 1 Diagnostic approach to patients with oculocutaneous albinism.

\section{Genetic counseling and antenatal diagnosis}

All five types of OCA-ID share an autosomal recessive pattern of inheritance. Therefore, the parents of a child with any of these conditions are usually obligate carriers of the disease and are asymptomatic. The risk of recurrence in a family with an affected child is $25 \%$. Although consanguinity may be suggestive, meanwhile, many cases are sporadic and family history may be negative.

Carrier detection and prenatal diagnosis are possible by molecular analysis of the causative gene after identification of the genetic mutation in the proband (affected individual). For prenatal diagnosis, genetic testing can be performed on DNA extracted from a chorionic villus sample (CVS) at 10-12 weeks gestation or cultured amniocytes. In principle, preimplantation diagnosis by molecular genetic analysis would be feasible following identification of the causative mutation(s) in the proband.

\section{Conclusion}

Differential diagnosis of Chediak-Higashi syndrome, Griscelli syndrome type 2, Hermansky-Pudlak syndrome type 2 and type 9 and MAPBPIP deficiency syndrome requires clinical, biochemical and molecular criteria. Clinical suspicion of OCA-ID should promptly lead to the performance of laboratory tests, including blood cell counting, blood smear analysis and immunoglobulin levels. In addition, clinical investigation of these patients should include assessment of NK or CTL cytotoxicity activity, light microscopic evaluation of hair and ophthalmological studies [Figure 1]. Finally, defining the causal genetic mutation may allow prompt institution of the appropriate treatments in affected patients and promote molecular tests in family members when necessary.

\section{Abbreviations}

CHS: Chediak Higashi syndrome; GS: Griscelli syndrome; HPS: Hermansky-Pudlak syndrome; OCA: Oculocutaneous Albinism; OCA-ID: Oculocutaneous Albinism and Immunodeficiency; NK: Natural Killer; CTL: Cytotoxic T cells;

HLH: Hemophagocytic lymphohistiocytosis; MHC II: Histocompatibility complex class II; HSCT: Hematopoietic Stem Cell Transplantation.

\section{Competing interests}

The authors declare no conflict of interests.

\section{Authors' contributions}

All authors contributed to a draft of the manuscript and were subsequently involved in revising the manuscript critically for important intellectual content. All authors read and approved the final manuscript.

\section{Acknowledgements}

This work was funded by grants from MIUR (PRIN2009) and EU Grant FP7 (HLH-cure) to R.B. 


\section{Author details}

${ }^{1}$ Department of Experimental and Clinical Sciences, Institute of Molecular Medicine "Angelo Nocivelli", University of Brescia, Brescia, Italy. ${ }^{2}$ Department of Molecular and Translational Medicine, University of Brescia, Brescia 25123 Italy. ${ }^{3}$ Center for Pediatric Genomic Medicine, Children's Mercy Hospital, Kansas City, MO 64108, USA. "Istituto di Medicina Molecolare "Angelo Nocivelli", Universita' di Brescia, c/o Spedali Civili, Brescia 25123, Italy.

Received: 12 May 2013 Accepted: 11 October 2013

Published: 17 October 2013

\section{References}

1. Grønskov K, Ek J, Brondum-Nielsen K: Oculocutaneous albinism. Orphanet J Rare Dis 2007, 2:43

2. Blott JE, Griffiths GM: Secretory lysosomes. Nat Rev Mol Cell Biol 2002, 3:122-131.

3. Clark R, Griffiths GM: Lytic granules, secretory lysosomes and disease. Curr Opin Immunol 2003, 15:516-521.

4. Stinchcombe J, Bossi G, Griffiths MG: Linking albinism and immunity: the secrets of secretory lysosomes. Science 2004, 305(5680):55-59.

5. Introne WJ, Westbroek W, Golas GA, Adams D: Chediak-Higashi syndrome In GeneReviews ${ }^{\mathrm{TM}}$. Edited by Pagon RA, Adam MP, Bird TD, Dolan CR, Fong CT, Stephens K. Seattle (WA): University of Washington, Seattle; 2009 [updated 2012] [http://www.ncbi.nlm.nih.gov/books/NBK5188/]

6. Menasche G, Pastural E, Feldmann J, Certain S, Ersoy F, Dupuis S, Wulffraat N, Bianchi D, Fischer A, Le Deist F, de Saint BG: Mutations in RAB27A cause Griscelli syndrome associated with haemophagocytic syndrome. Nat Genet 2000, 25(2):173-176.

7. Arico M, Janka G, Fisher A, Martinetti M, Rusca MP: Haemophagocytic lymphohistiocytosis. Report of 122 children from the International Registry. FLH Study Group of the Histiocyte Society. Leukemia 1996, 10(2):197-203

8. Horne A, Trottestam H, Aricò M, Egeler RM, Filipovich AH, Gadner $\mathrm{H}_{\text {, }}$ Imashuku S, Ladisch S, Webb D, Janka G, Henter J, Histiocyte Society: Frequency and spectrum of central nervous system involvement in 193 children with haemophagocytic lymphohistiocytosis. Br J Haematol 2008 140(3):327-335.

9. Perez N, Virelizier UL, Arenzana-Seisdedos F, Fischer A, Griscelli C: Impaired natural killer activity in lymphohistiocytosis syndrome. J Pediatr 1984, 104(4):569-573.

10. Nargund AR, Madhumathi DS, Premalatha CS, Rao CR, Appaji L, Lakshmidevi V: Accelerated phase of Chediak-Higashi syndrome mimicking lymphomaa case report. J Pediatr Hematol Oncol 2010, 32(6):e223-e226.

11. Sieni E, Cetica V, Mastrodicasa E, Pende D, Moretta L, Griffiths G, Aricò M: Familial hemophagocytic lymphohistiocytosis: a model for understanding the human machinery of cellular cytotoxicity. Cell Mol Life Sci 2012, 69(1):29-40

12. Chediak MM: New leukocyte anomaly of constitutional and familial character. Rev Hematol 1952, 7:362-367.

13. Blume RS, Wolff SM: The Chediak-Higashi syndrome: studies in four patients and a review of the literature. Medicine 1972, 51:247-280.

14. Introne W, Boissy RE, Gahl WA: Clinical, molecular, and cell biological aspects of Chediak-higashi syndrome. Mol Genet Metab 1999, 68:283-303.

15. Pujani M, Agarwal K, Bansal S, Ahmad I, Puri V, Verma D, Pujani M: ChediakHigashi syndrome - a report of two cases with unusual hyperpigmentation of the face. Turkish J Pathol 2011, 27(3):246-248.

16. Khocht A, Viera-Negron YE, Ameri A, Abdelsayed R: Periodontitis associated with Chediak-Higashi syndrome in a young African American Male. J Int Acad Periodontol 2010, 12(2):49-55.

17. Nagle DL, Karim MA, Woolf EA, Holmgren L, Bork P, Misumi DJ, McGrail SH, Dussault BJ Jr, Perou CM, Boissy RE, Duyk GM, Spritz RA, Moore KJ: Identification and mutation analysis of the complete gene for ChediakHigashi syndrome. Nat Genet 1996, 14:307-311.

18. Barbosa MDFS, Nguyen QA, Tchernev VT, Ashley JA, Detter JC, Blaydes SM, Brandt SJ, Chotai D, Hodgman C, Solari RC, Lovett M, Kingsmore SF: Identification of the homologous beige and Chediak-Higashi syndrome genes. Nature 1996, 382:262-265.

19. Barbosa MD, Barrat FJ, Tchernev VT, Nguyen QA, Mishra VS, Colman SD, Pastural E, Dufourcq-Lagelouse R, Fischer A, Holcombe RF, Wallace MR, Brandt SJ, de Saint BG, Kingsmore SF: Identification of mutations in two major mRNA isoforms of the Chediak-Higashi syndrome gene in human and mouse. Hum Mol Genet 1997, 6(7):1091-1098.

20. Perou CM, Leslie JD, Green W, Li L, Ward DM, Kaplan J: The Beige ChediakHigashi syndrome gene encodes a widely expressed cytosolic protein. J Biol Chem 1997, 272(47):29790-29794.

21. Durchfort N, Verhoef S, Vaughn MB, Shrestha R, Adam D, Kaplan J, Ward DM: The enlarged lysosomes in beige $\mathrm{j}$ cells result from decreased lysosome fission and not increased lysosome fusion. Traffic 2012 Jan, 13(1):108-119

22. Tchernev VT, Mansfield TA, Giot L, Kumar AM, Nandabalan K, Li Y, Mishra VS, Detter JC, Rothberg JM, Wallace MR, Southwick FS, Kingsmore SF: The Chediak-Higashi protein interacts with SNARE complex and signal transduction proteins. Mol Med 2002 Jan, 8(1):56-64.

23. Shiflett SL, Kaplan J, Ward DM: Chediak-Higashi syndrome: a rare disorders of lysosomes and lysosomes related organelles. Pigment Cell Res 2002, 15:251-257.

24. Ward DM, Shiflett SL, Kaplan J: Chediak-Higashi syndrome: a clinical and molecular view of a rare lysosomal storage disorder. Curr Mol Med 2002, 2(5):469-477.

25. Ward DM, Shiflett S, Huynh D, Vaughn M, Prestwich G, Kaplan J: Use of expression contructs to dissect the functional domains of the CHS/ Beige protein: identification of multiple phenotypes. Traffic 2003 4:403-415.

26. Karim MA, Suzuki K, Fukai K, Oh J, Nagle DL, Moore KJ, Barbosa E, Falik-Borenstein T, Filipovich A, Ishida Y, Kivrikko S, Klein C, Kreuz F, Levin A, Miyajima H, Regueiro J, Russo C, Uyama E, Vierimaa O, Spritz RA: Apparent genotype-phenotype correlation in childhood, adolescent, and adult Chediak Higashi syndrome. Am J Med Genet 2002, 108:16-22.

27. Westbroek W, Adams D, Huizing M, Koshoffer A, Dorward H, Tinloy B, Parkes J, Helip-Wooley A, Kleta R, Tsilou E, Duvernay P, Digre KB, Creel DJ, White JG, Boissy RE, Gahl WA: The severity of cellular defects in Chediak Higashi Syndrome correlate with the molecular genotype and clinical phenotype. J Invest Dermatol 2007, 127:2674-2677.

28. Tanabe F, Kasai H, Morimoto M, Oh S, Takada H, Hara T, Ito M: Nove heterogenous CHS1 mutations identified in five japanese patients with Chediak-Higashi syndrome. Case Report Med 2010, 2010:464671.

29. Rendu F, Breton-Gorius J, Lebret M, Klebanoff C, Buriot D, Griscelli C, Levy-Toledano S, Caen JP: Evidence that abnormal platelet functions in human Chediak-Higashi-syndrome are the result of a lack of dense bodies. Am J Pathol 1983, 111:307-314.

30. Apitz-Castro R, Cruz MR, Ledezma E, Merino F, Ramirez-Duque $P$, Dangelmeier $\mathrm{C}$, Holmsen $\mathrm{H}$ : The storage pool deficiency in platelets from humans with the Chediak-Higashi syndrome: study of six patients. $\mathrm{Br} J$ Haematol 1985, 59:471-483.

31. Kjeldsen L, Calafat J, Borregaard N: Giant granules of neutrophils in Chediak-Higashi syndrome are derived from azurophil granules but not from specific and gelatinase granules. J Leukoc Biol 1998, 64:72-77.

32. Clawson CC, White JG, Repine JE: The Chediak-Higashi syndrome: Evidence that defective leukotaxis is primarily due to an impediment by giant granules. Am J Pathol 1978, 92:745-754.

33. Haliotis T, Roder J, Klein M, Ortaldo J, Fauci AS, Herberman RB: ChediakHigashi gene in humans I. Impairment of natural-killer function. J Exp Med 1980, 151:1039-1048.

34. Stinchcombe JC, Griffiths GM: Regulated secretion from hemopoietic cells. J Cell Biol 1999, 147:1-6.

35. Kaplan J, De Domenico I, Ward DM: Chediak-Higashi syndrome. Curr Opin Hematol 2008, 15(1):22-29.

36. Eapen M, DeLaat CA, Baker KS, Cairo MS, Cowan MJ, Kurtzberg J, Steward CG, Veys PA, Filipovich AH: Hematopoietic cell transplantation for ChediakHigashi syndrome. Bone Marrow Transplant 2007, 39:411-415.

37. Griscelli C, Durandy A, Guy-Grand D, Daguillard F, Herzog C, Prunieras M: A syndrome associating partial albinism and immunodeficiency. Am J Med 1978, 65:691-702

38. Pastural E, Barrat FJ, Dufourcq-Lagelouse R, Certain S, Sanal O, Jabado N, Seger R, Griscelli C, Fischer A, de Saint Basile G: Griscelli disease maps to chromosome 15q21 and is associated with mutations in the myosin-Va gene. Nat Genet 1997, 16:289-292.

39. Menasche G, Ho CH, Sanal O, Feldmann J, Tezcan I, Ersoy F, Houdusse A Fischer A, de Saint BG: Griscelli syndrome restricted to hypopigmentation results from a melanophilin defect (GS3) or a MYO5A F-exon deletion (GS1). J Clin Invest 2003, 112(3):450-456. 
40. Kurugol Z, Ozkinay F, Vardar F, Karaçali S, Kutukçuler N, Deveci R, Ozkinaj C: Griscelli syndrome: report of a case and review of the literature. Pediatr Int 2001, 43:298-301.

41. Meeths M, Bryceson YT, Rudd E, Zheng C, Wood SM, Ramme K, Beutel K, Hasle H, Heilmann C, Hultenby K, Ljunggren HG, Fadeel B, Nordenskjöld M, Henter Jl: Clinical presentation of Griscelli syndrome type 2 and spectrum of RAB27A mutations. Pediatr Blood Canc 2010, 54:563-572.

42. Meschede IP, Santos TO, Izidoro-Toledo TC, Gurgel-Gianetti J, Espreafico EM: Griscelli syndrome-type 2 in twinsiblings: case report and update on RAB27A human mutations and gene structure. Braz J Med Biol Res 2008, 41(19):839-848.

43. Schuster F, Stachel DK, Schmid I, Baumeister FA, Graubner UB, Weiss M, Haas RJ, Belohradsky BH: Griscelli syndrome: report of the first peripheral blood stem cell transplant and the role of mutations in the RAB27A gene as an indication for BMT. Bone Marrow Transplant 2001, 28:409-412.

44. Arico M, Zecca M, Santoro N, Caselli D, Maccario R, Danesino C, de Saint BG, Locatelli F: Successful treatment of Griscelli syndrome with unrelated donor allogeneic hematopoietic stem cell transplantation. Bone Marrow Transplant 2002, 29(12):995-998.

45. Blanche S, Caniglia M, Girault D, Landman J, Griscelli C, Fischer A: Treatment of hemophagocytic lymphohistiocytosis with chemotherapy and bone marrow transplantation: a single-center study of 22 cases. Blood 1991, 78:51-54.

46. Bizario JC, Feldmann J, Castro FA, Menasche G, Jacob CM, Cristofani L, Casella EB, Voltarelli JC, de Saint-Basile G, Espreafico EM: Griscelli syndrome: characterization of a new mutation and rescue of T-cytotoxic activity by retroviral transfer of RAB27A gene. J Clin Immunol 2004, 24(4):397-410.

47. Wei ML: Hermansky-Pudlak syndrome: a disease of protein trafficking and organelle function. Pigment Cell Res 2006, 19(1):19-42.

48. Huizing M, Anikster Y, Gahl WA: Hermansky-Pudlak Syndrome and Related Disorders of Organelle Formation. Traffic 2000, 1(11):823-835.

49. Huizing M, Scher CD, Strovel E, Fitzpatrick DL, Hartnell LM, Anikster Y, Gahi WA: Nonsense mutations in ADTB3A cause complete deficiency of the \{beta\}3a subunit of adaptor complex-3 and severe Hermansky- Pudlak syndrome type 2. Pediatr Res 2002, 51:150-158.

50. Lorenzi L, Tabellini G, Vermi W, Moratto D, Porta F, Notarangelo LD, Patrizi O, Sozzani S, de Saint Basile G, Latour S, Pace D, Lonardi S, Facchetti F, Badolato R, Parolini S: Occurrence of Nodular Lymphocyte-Predominant Hodgkin Lymphoma in Hermansky-Pudlak type 2 syndrome is associated to Natural Killer and Natural Killer T cell defects. PLOS One.

51. Enders A, Zieger B, Schwarz K, Yoshimi A, Speckmann C, Knoepfle EM, Kontny U, Müller C, Nurden A, Rohr J, Henschen M, Pannicke U, Niemeyer C, Nurden P, Ehl S: Lethal hemophagocytic lymphohistiocytosis in Hermansky- Pudlak syndrome type II. Blood 2006, 108(1):81-86.

52. Dell'Angelica EC, Shotelersuk V, Aguilar RC, Gahl WA, Bonifacino JS: Altered trafficking of lysosomal proteins in Hermansky-Pudlak syndrome due to mutations in the beta 3A subunit of the AP-3 adaptor. Mol Cell 1999, 3:11-21.

53. Rodriguez-Boulan E, Kreitzer G, Müsch A: Organization of vesicular trafficking in epithelia. Nat Rev Mol Cell Biol 2005, 6(3):233-247.

54. Bonifacino JS, Traub LM: Signals for sorting of transmembrane proteins to endosomes and lysosomes. Annu Rev Biochem 2003, 72:395-447.

55. Badolato R, Parolini S: Novel insights from adaptor protein 3 complex deficiency. J Allergy Clin Immunol 2007, 120:735-741.

56. Fontana S, Parolini S, Vermi W, Booth S, Gallo F, Donini M, Benassi M, Gentili F, Ferrari D, Notarangelo LD, Cavadini P, Marcenaro E, Dusi S, Cassatella M, Facchetti F, Griffiths GM, Moretta A, Notarangelo LD, Badolato R: Innate immunity defects in Hermansky-Pudlak type 2 syndrome. Blood 2006, 107(12):4857-4864

57. Clark R, Stinchcombe JC, Day A, Blott E, Booth S, Bossi G: Adaptor protein 3-dependent microtubule-mediated movement of lytic granules to the immunological synapse. Nat Immunol 2003, 4(11):1111-1120.

58. Horwitz MS, Duan Z, Korkmaz B, Lee HH, Mealiffe ME, Salipante SJ: Neutrophil elastase in cyclic and severe congenital neutropenia. Blood 2007, 109:1817-1824.

59. Sugita M, Cao X, Watts GF, Rogers RA, Bonifacino JS, Brenner MB: Failure of trafficking and antigen presentation by CD1 in AP-3- deficient cells. Immunity 2002, 16:697-706.

60. Caplan S, Dell'Angelica EC, Gahl WA, Bonifacino JS: Trafficking of major histocompatibility complex class II molecules in human B-lymphoblasts deficient in the AP-3 adaptor complex. Immunol Lett 2000, 72:113-117.
61. Sevilla LM, Richter SS, Miller J: Intracellular transport of MHC class II and associated invariant chain in antigen presenting cells from AP-3- deficient mocha mice. Cell Immunol 2001, 210:143-153.

62. Elewaut D, Lawton AP, Nagarajan NA, Maverakis E, Khurana A, Honing S, Benedict CA, Sercarz E, Bakke O, Kronenberg M, Prigozy TI: The adaptor protein AP-3 is required for CD1d-mediated antigen presentation of glycosphingolipids and development of Valpha14i NKT cells. J Exp Med 2003, 198:1133-1146.

63. Cullinane AR, Curry JA, Carmona-Rivera C, Summers CG, Ciccone C, Cardillo ND, Dorward H, Hess RA, White JG, Adams D, Huizing M, Gahl WA: A BLOC-1 mutation screen reveals that PLDN is mutated in Hermansky-Pudlak Syndrome type 9. Am J Hum Genet 2011, 88(6):778-787.

64. Badolato R, Prandini A, Caracciolo S, Colombo F, Tabellini G, Giacomelli M, Cantarini ME, Pession A, Bell CJ, Dinwiddie DL, Miller NA, Hateley SL, Saunders CJ, Zhang L, Schroth GP, Plebani A, Parolini S, Kingsmore SF: Exome sequencing reveals a pallidin mutation in a Hermansky-Pudlaklike primary immunodeficiency syndrome. Blood 2012, 119(13):3185-3187.

65. Bohn G, Allroth A, Brandes G, Thiel J, Glocker E, Schäffer AA, Rathinam C, Taub N, Teis D, Zeidler C, Dewey RA, Geffers R, Buer J, Huber LA, Welte K, Grimbacher B, Klein C: A novel human primary immunodeficiency syndrome caused by deficiency of the endosomal adaptor protein p14. Nat Med 2007, 13:38-45.

66. Wunderlich W, Fialka I, Teis D, Alpi A, Pfeifer A, Parton RG, Lottspeich F, Huber LA: A novel 14-kilodalton protein interacts with the mitogenactivated protein kinase scaffold $\mathrm{mp} 1$ on a late endosomal/lysosomal compartment. J Cell Biol 2001, 152(4):765-776.

67. Kurzbauer R, Teis D, de Araujo ME, Maurer-Stroh S, Eisenhaber F, Bourenkov GP, Bartunik HD, Hekman M, Rapp UR, Huber LA, Clausen T: Crystal structure of the p14/MP1 scaffolding complex: how a twin couple attaches mitogenactivated protein kinase signaling to late endosomes. Proc Natl Acad Sci U S A 2004, 101(30):10984-10989.

68. Badolato R, Fontana S, Notarangelo LD, Savoldi G: Congenital neutropenia: advances in diagnosis and treatment. Curr Opin Allergy Clin Immunol 2004, 4:513-521.

69. Kingsmore SF, Dinwiddie DL, Miller NA, Soden SE, Saunders CJ: Adopting orphans: comprehensive genetic testing of Mendelian diseases of childhood by next-generation sequencing. Expert Rev Mol Diagn 2011, 11:855-868.

70. Bainbridge MN, Wiszniewski W, Murdock DR, Friedman J, Gonzaga-Jauregui C Newsham I, Reid JG, Fink JK, Morgan MB, Gingras MC, Muzny DM, Hoang LD, Yousaf S, Lupski JR, Gibbs RA: Whole-genome sequencing for optimized patient management. Sci Transl Med 2011, 3(87):87re3.

71. Kingsmore SF, Saunders CJ: Deep sequencing of patient genomes for disease diagnosis: When will it become routine? Sci Transl Med 2011, 3:87ps23.

72. Gonzaga-Jauregui C, Lupski JR, Gibbs RA: Human genome sequencing in health and disease. Annu Rev Med 2012, 63:35-61.

73. Lupski JR, Reid JG, Gonzaga-Jauregui C, Rio Deiros D, Chen DC, Nazareth L, Bainbridge $M$, Dinh $H$, Jing C, Wheeler DA, McGuire AL, Zhang F, Stankiewicz P, Halperin JJ, Yang C, Gehman C, Guo D, Irikat RK, Tom W, Fantin NJ, Muzny DM, Gibbs RA: Whole-genome sequencing in a patient with Charcot-Marie-Tooth Neuropathy. N Engl J Med 2010, 362:1181-1191.

74. Worthey EA, Mayer AN, Syverson GD, Helbling D, Bonacci BB, Decker B: Making a definitive diagnosis: successful clinical application of whole exome sequencing in a child with intractable inflammatory bowel disease. Genet Med 2011, 13:255-262.

75. [No authors listed]: American College of Medical Genetics and Genomics (ACMG) Policy Statement, Points to Consider in the Clinical Application of Genomic Sequencing. 2012.

76. Saunders CJ, Miller NA, Soden SE, Dinwiddie DL, Noll A, Alnadi NA, Andraws N, Patterson ML, Krivohlavek LA, Fellis J, Humphray S, Saffrey P, Kingsbury Z, Weir JC, Betley J, Grocock RJ, Margulies EH, Farrow EG, Artman M, Safina NP, Petrikin JE, Hall KP, Kingsmore SF: Rapid whole-genome sequencing for genetic disease diagnosis in neonatal intensive care units. Sci Trans/ Med 2012, 4(154):154ra135.

\section{doi:10.1186/1750-1172-8-168}

Cite this article as: Dotta et al.: Clinical, laboratory and molecular signs of immunodeficiency in patients with partial oculo-cutaneous albinism. Orphanet Journal of Rare Diseases 2013 8:168. 